Western University

Scholarship@Western

Department of Economics Research Reports

Economics Working Papers Archive

1991

\title{
On the Social Optimality of Liquidated Damage Clauses: An Economic Analysis
}

Tai-Yeong Chung

Follow this and additional works at: https://ir.lib.uwo.ca/economicsresrpt

Part of the Economics Commons

Citation of this paper:

Chung, Tai-Yeong. "On the Social Optimality of Liquidated Damage Clauses: An Economic Analysis." Department of Economics Research Reports, 9102. London, ON: Department of Economics, University of Western Ontario (1991). 
ISBN : 0-7714-1267-3

\section{RESEARCH REPORT 9102}

ON THE SOCIAL OPTIMALITY OF LIQUIDATED

DAMAGE CLAUSES: AN ECONOMIC ANALYSIS

by

Tai-Yeong Chung

February 1991

Department of Economics

Social Science Centre

University of Western Ontario

London, Ontario, Canada

N6A $5 C 2$

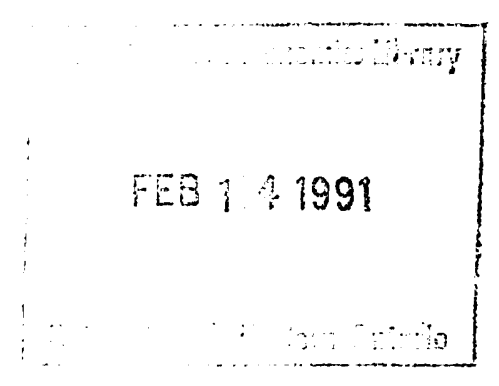




\section{On the Social Optimality of Liquidated Damage Clauses : \\ An Economic Analysis *}

by

Tai-Yeong Chung **

October 1989

Revised November 1990

* This work is based on Chapter 2 of my dissertation completed at Northwestern University. I would like to thank Lawrence Ausubel, Raymond Denecker, Steven Matthews, Ian MacNeil, Mark Grady, John Panzar, A. Mitchell Polinsky, Richard Posner, Steven Shavell, Steven Williams, and the seminar participants at Cal Tech, OSU, U. Penn, Princeton, Queen's, Toronto, UBC, UCLA, U. Washington, U. Western Ontario, and the 6th World Congress of The Econometric Society. I would like to particularly thank William Rogerson for many useful discussions and comments. This work has been financially supported by Alfred P. Sloan Doctoral Dissertation Fellowship. Any remaining errors are mine.

** Please send all correspondences to Department of Economics, University of Western Ontario, London, Ontario N6A 5C2, Canada. 


\section{Abstract}

"On the Social Optimality of Liquidated damage Clauses: An Economic Analysis" by

Tai-Yeong Chung

The courts have imposed limitations on the ability of contractual parties to stipulate their own remedies for breach of contract. The most important restriction denies them the power to stipulate damages that are so large as to be characterized as penalties. The main purpose of this paper is to clarify some of puzzling aspects of the 'penalty doctrine' by providing an economic analysis. It is shown that the rule of freedom of contract under which any liquidated damages are enforced could generate social inefficiency by allowing contracting parties to impose external costs on potential competitors. The rule of penalty doctrine under which unreasonably large liquidated damages are unenforceable could mitigate the inefficiency by placing a cap on the enforceable liquidated damages. It is also shown that the rule of penalty doctrine could mitigate over-investment problems which occur under the traditionally used expectation remedy. 


\section{Introduction}

The principle of freedom of contract rests on the premise that it is in the public interest to accord individuals broad powers to order their affairs through legally enforceable agreements with the courts enforcing them without passing on their substance. Occasionally, however, a court will decide that the public interest in freedom of contract is outweighed by other considerations and refuse to enforce the agreement or some part of it on that ground. In particular, contracting parties' power to bargain over their remedial rights is surprisingly limited. The most important restriction denies them the power to stipulate damages that are so large as to be characterized as penalties. ${ }^{1}$

The failure of courts to enforce penalties has been a puzzle to economists. ${ }^{2}$ Economists generally believe that any contract voluntarily made between two rational parties is efficient, for parties do not enter into agreements which do not benefit them. Based on this belief, several authors argue that any stipulated damages, including penalties, should be fully enforced. ${ }^{3,4}$ On the other hand, it has been also argued that penalties could induce inefficiency by preventing an efficient breach. ${ }^{5}$ This argument cannot be a complete justification for the judicial policy against penalties unless it can be shown that the use of penalties, which are claimed to be inefficient, is in the interest of the parties to a contract. The source of difficulty in providing a rationale for this legal practice on penalties lies in the fact that we have not had a formal framework in which both the private interest in freedom of contract and the social interest in public policy can be examined in a consistent way. ${ }^{6}$

The main purpose of this paper is to provide a formal framework in which this puzzle can be explained in a consistent way by using economic theory, in particular, by using the concept of externality. The central argument is that a contract which is optimal for the contracting parties may be inefficient from the social perspective if the contract has an external effect on third parties (i.e., non-parties to the contract). It is shown in this article that 
contracting parties may have an incentive to stipulate penalties which induce social inefficiency by preventing potential actors from competing with the parties to the contract.

Once such a formal framework is constructed, the welfare and policy implications of current legal practice can be examined and new policies on contract remedies can be proposed. Specifically, three different rules of awarding damages are considered in this article. The first rule is that of freedom of contract ( $F C$ rule) in which the courts enforce any stipulated damages. The second rule is to ignore any stipulated damages, and apply the expectation damage measure ( $E D$ rule). The third rule is to apply the penalty doctrine under which over-compensatory stipulated damages are unenforceable ( $P D$ rule).

Two major results are derived. First, it is shown, in a model of fixed reliance, that the $P D$ rule is more efficient than the $F C$ rule. The intuition behind this result is as follows. When there are externalities, contracting parties have an incentive to stipulate a penalty clause which, if enforced, will induce social inefficiency by preventing potential actors from competing with the parties to the contract. The $F C$ rule is socially inefficient since it allows the penalty clause to be enforced, while the $P D$ rule can mitigate this inefficiency by placing a cap on the enforceable stipulated damages.

The second major result of this article is that, in a model of variable reliance, the PD rule is at least as efficient as the $E D$ rule. It is well established in the literature that the $E D$ rule induces over-investment by the promisee (the breached-against party). It is shown in this article that the $P D$ rule can mitigate the problem of over-investment which occurs under the $E D$ rule. The key idea behind this result is that the stipulated damages under the $P D$ rule is invariant with respect to the reliance investment.

The basic situation considered in this article is the one in which parties to a contract face an uncertain offer (or bid) from a third party for the contractual performance agreed to by the parties. ${ }^{7}$ In considering this problem, Shavell (1980) assumed that the third party's (say, a new buyer's) bid is the same as his valuation, and he compared the efficiencies of several familiar damage measures for breach of contracts. The assumption that the third party makes 
the same bid as his true valuation is strong, and it amounts to assuming that the third party does not have any bargaining power. This article generalizes Shavell's work by endogenizing the third party's bidding behavior to examine the implications of externalities a contract may generate, and evaluates the penalty doctrine by explicitly considering the possibility that the parties may stipulate a damage payment.

Suppose that the third party has some bargaining power in determining his bid. Then, his bid will generally depend upon whatever information he has on the contractual situation - for example, contract price, liquidated damages, level of specific-investments made by the contracting parties. Therefore, when the third party has some discretionary power in deciding his bid, there is a room for the contract terms to affect his bidding behavior. Since the terms of original contract are designed without considering their effect on outside party, there is potentially an externality. ${ }^{8}$ Thus, the source of externality in this article is the fact that the third party has some bargaining power in making his bid to one of the contracting parties, and he could not participate in making the original contract.

The idea of using externalities to resolve this puzzle is not completely novel. 9 Rubin (1981) pointed out that since all contracts signed by two parties must be value maximizing vis-a-vis those parties, an efficiency explanation for the courts' refusal to enforce such agreements must be in terms of effects of the contracts on third parties. Rubin's main argument is that such contracts impose burdens on the court system which lead parties to sign agreements that may not be value maximizing; moreover, the litigation resulting from enforcement of these contracts provides no useful information to other potential disputants. ${ }^{10}$ This article focuses on the implication of externalities which are imposed on potential competitors, not on the costly judicial system.

The result that an equilibrium contract specifying liquidated damages could incur social inefficiencies has been shown in both Diamond and Maskin (1979), and Aghion and Bolton (1987). In Diamond and Maskin (1979), the effects on search as well as breach decisions of compensatory damages and liquidated damages are considered. They show that liquidated 
damages induces too little breach and too much search decisions under a specific meeting technology, while compensatory damages induces both efficient breach and search decisions. On the other hand, Aghion and Bolton show that a contract serves as a barrier to entry (of the third party) so that it has an anti-competitive effect.

The applicability of their theoretical constructions in addressing the important legal issues considered in this article has not been recognized. This article differs, however, from their papers in that, first, it addresses important policy issues on legal rules governing contract damages, and second, it explicitly considers the role of relationship-specific investments for the design of such legal rules.

The article is organized as follows. Section 2 sets up the model. Section 3 provides formal definitions of the three rules described above. Section 4 considers two special cases for the purpose of contrast - first, when the court has perfect information, and second, when there is no externality. Section 5 contains the formal analysis of the model under the assumption that the court has imperfect information and there is an externality. Subsection 5.1 considers the cases in which reliance investment is fixed, and provides the result that the social inefficiency of the $F C$ rule can be mitigated by the $P D$ rule. Subsection 5.2 considers the cases in which reliance investment is variable, and provides the result that the overinvestment with the $E D$ rule can be mitigated by the $P D$ rule. Section 6 considers an application of the main argument of this article to tort law. Concluding remarks appear in

Section 7. For expositional simplicity, the proofs of Section 5 are relegated to the Appendix, and only intuitive explanations are given in the text.

\section{Model}

In the model to be examined, a buyer makes a contract with a seller for the delivery of an indivisible good (or the performance of a service). Once the contract is made, the buyer may have to decide on his level of reliance. ${ }^{11}$ The fundamental uncertainty of the model is on the 
valuation of the good to a new buyer whose identity is not known initially. It is important to note that the potential new buyer could not participate in the initial contract. After the buyer makes his reliance investment, the new buyer learns his valuation of the good and may make a bid for the good. If the new buyer makes a bid, the seller has to decide which buyer to supply.

The case in which a new seller makes an offer to the buyer can be analyzed in a symmetric way with some changes in notation. Therefore, the buyer in this article is viewed as a promisee, or breached-against party, while the seller is viewed as a promisor, or breaching party. The new buyer is viewed as a third party who makes an offer or bid to the promisor that may induce a breach of contract.

Let $B$ denote the (incumbent) buyer, $S$ the seller, and $T$ the third party (the new buyer). It is assumed that all three parties are risk neutral. ${ }^{12}$ Let $r \in R_{+}$denote $B$ 's reliance. It is assumed that reliance is measured in dollars. Given $B$ 's reliance level $r$, let $v(r)$ denote his gross utility of the good. It is assumed, without loss of generality, that when $B$ does not get the good, his utility is zero. Therefore, $v(r)$ can be viewed as the incremental utility to $B$ of getting the good given $r$. It is further assumed, without loss of generality, that $S$ can produce and supply the good to $B$ at zero cost. Let $c$ denote $S$ 's cost of supplying the good to $T$. Now, $c$ can be regarded as the incremental cost of supplying the good to $T$ rather than to $B .{ }^{13}$ Let $\theta$ denote $T$ s valuation of the good. It is assumed that $\theta$ has a continuous positive density $f(\theta)$ over a closed interval $[\underline{\theta}, \bar{\theta}]$ and $F(\theta)$ is the corresponding distribution function. It is assumed that $\theta$ is non-verifiable (to the court). ${ }^{14}$ Let $z$ denote $T$ 's bid. The determination of the equilibrium bid price $z(\theta)$ will be described shortly.

Only simple contracts are considered in this article. ${ }^{15} \mathrm{~A}$ typical contract to be considered is a pair of prices, $(p, x)$ where $p$ denotes the payment for the good from $B$ to $S$ which is paid at the time of contracting, and $x$ denotes the gross damage payment from $S$ to $B$ when $B$ does not get the good ( $x-p$ is the net damage payment). ${ }^{16}$ The payoffs to the parties depend on the identity of the party who gets the good and also on the realization of the uncertain 
valuation. Let $(p, x)$ be a contract, $r$ reliance investment, and $\theta$ the realization of $T$ 's valuation. Then, when $B$ gets the good, $B^{\prime}$ 's utility is $v(r)-p-r, S^{\prime}$ s utility is $p$, and $T$ 's utility is zero. On the other hand, when $T$ gets the good, $B$ 's utility is $x-p-r, S$ 's utility is $p$ $+z(\theta)-x-c$, and $T^{\prime}$ 's utility is $\theta-z(\theta) .17$

In some cases, a damage payment is not specified in a contract, but it is determined by the court if a breach occurs. If there is a routine damage measure enforced by the court, then $x$ could be interpreted as the damage level and is no longer a choice variable of the parties (in that case, it is assumed that the routine damage measure is common knowledge among all the parties). The damage payment $x$ can be a function of various variables such as $p, r$, etc., but it cannot be a function of $\theta$, since $\theta$ is assumed to be non-verifiable. In this article, my attention is restricted to constant damage payments stipulated by the parties, and the expectation damages which are in general a function of the buyer's reliance decision $r{ }^{18,} 19$

Since the timing of the model is crucial, this is now explicitly outlined. At some initial time, $B$ and $S$ make a contract of the form $(p, x) .20$ It is assumed that contract terms are public information (i.e., these will be known to $T$ ). Then $B$ makes his reliance decision on $r$. It is assumed that $r$ is non-contractible. Once the reliance decision is made, it is assumed that it is observable by all three parties. Next, the valuation to $T$ of the good, $\theta$, is realized, and it is assumed to be observable by all three parties. After that, $T$ may make a bid of $z(\theta)$ to $S$, and $S$ must decide which buyer he will serve. Next, the contract is finally executed, and disputes, if any, are resolved.

Three major assumptions on the behavior of the parties are made. First, it is assumed that the seller cannot supply the good to both buyers, presumably due to capacity limitations. Second, no resale between buyers is allowed. This assumption can be easily satisfied for the case of the performance of services, e.g., construction contracts. If resale were possible (in cases of easily tradable goods such as stocks), then other remedies such as specific performance or injunction may play important roles. Third, it is assumed that no renegotiation of the contract terms is allowed. This is not an innocuous assumption. If 
renegotiation were feasible, the buyer with the highest value would get the good, given the reliance decision made. ${ }^{21}$ Even with renegotiation, the first-best outcomes cannot always be implemented, for different damage rules provide different incentives for reliance decision. Since allowing for renegotiation would require another lengthy analysis, it is not considered in this article. It suffices to say that if there are some negotiation costs or imperfections in bargaining, then all of results in this article are valid.

To complete the model, $T$ 's bidding behavior must be specified. In this article, the price bid by $T$ is modelled as depending on a parameter interpreted with $T$ 's negotiation power. At one extreme, $T$ has no negotiation power and makes a bid equal to his true valuation, i.e., $z(\theta)=\theta$ for all $\theta .22$ At the other extreme, in which $T$ has all the negotiation power, the bidding price is determined as follows. Given a contract $(p, x)$ and reliance $r, S$ will accept a bid $z$ if $p+z-x-c \geq p$, or equivalently if $z \geq x+c$. Hence, if $\theta \geq x+c$, then $T$ will make a bid $z(\theta)=x+c$ at which he will get the good. Otherwise, $T$ will not make any bid (or zero bid), and $B$ will get the good. ${ }^{23}$ Now, let $\alpha \in[0,1]$ denote $T$ 's relative negotiation power. Then, the equilibrium price bid is defined by

$$
z(\theta, x, \alpha) \equiv(1-\alpha) \theta+\alpha(x+c)
$$

$T$ will get the good at $z(\theta, x, \alpha)$ if $\theta \geq z(\theta, x, \alpha)$, or equivalently if $\theta \geq x+c$. In that case, the switching of buyer from $B$ to $T$ leads to a breach of the contract between $B$ and $S$. Given a contract $(p, x)$ and reliance $r$, the probability of the event that $T$ gets the good is defined by

$$
\Phi(x) \equiv \operatorname{Prob}\{\theta \in[\underline{\theta}, \dot{\theta}]: \theta \geq z(\theta, x, \alpha)\}=1-F(x+c)
$$

Note that the probability does not directly depend on $\alpha$, and it depends on the contract terms through $x$, not through $p$. Since it turns out that reliance decisions also depend on contract terms only through $x$, the explicit determination of $p$ is not analyzed in this article. 
Now derive each party's expected utility from a given contract $(p, x)$ and reliance $r$. Let $U^{B}, U^{S}$, and $U^{T}$ denote the expected utility of $B, S$, and $T$ respectively. Let $\Omega \equiv\{\theta \in[\theta, \bar{\theta}]\}$ $\theta \geq x+c\}$, and $\Omega^{\mathcal{E}} \equiv[\underline{\theta}, \bar{\theta}] \backslash \Omega$. Let $\alpha \in[0,1]$ be given. Then

$$
\begin{aligned}
U^{B}(r, x, p) & =\int_{\Omega} f[v(r)-r-p] d F(\theta)+\int_{\Omega}[x-r-p] d F(\theta) \\
& =v(r)-r-p+[1-F(x+c)][x-v(r)] \\
U^{S}(r, x, p ; \alpha) & =\int_{\Omega} f[p] d F(\theta)+\int_{\Omega}[p+z(\theta, x, \alpha)-x-c] d F(\theta) \\
& =p+(1-\alpha) \int_{\Omega}[\theta-(x+c)] d F(\theta) \\
U^{T}(r, x, p ; \alpha) & =\int_{\Omega}[\theta-z(\theta, x, \alpha)] d F(\theta) \\
& =\alpha \int_{\Omega}[\theta-(x+c)] d F(\theta)
\end{aligned}
$$

In (3), the term $[x-v(r)]$ is the gain to $B$ due to the switch from $B$ to $T$, since $v(r)$ is the loss from not getting the good, and $x$ is the gross damage payment which $B$ would receive if he does not get the good. In (4) and (5), the term $\int_{\Omega}[\theta-(x+c)] d F(\theta)$ reflects total gains from the expected switching of buyers, and it is distributed between $S$ and $T$ according to their negotiation power so that $\alpha$ is $T$ 's share of the total gains from the expected switching of buyers.

Define $U^{B+S} \equiv U^{B}+U^{S}$ to be the joint expected utility function of the contracting parties, and $W \equiv U^{B}+U^{S}+U^{T}$ to be the social welfare function. ${ }^{24}$ Formally,

$$
\begin{aligned}
U^{B+S}(r, x) & =v(r)-r+[1-F(x+c)][x-v(r)] \\
& +(1-\alpha) \int_{\Omega}[\theta-(x+c)] d F(\theta) \\
W(r, x)= & v(r)-r+[1-F(x+c)][x-v(r)] \\
& +\int_{\Omega}[\theta-(x+c)] d F(\theta)
\end{aligned}
$$


Note that when $\alpha=0, U^{B+S}(r, x)=W(r, x)$ for all $r, x$. In other words, when there are no externalities, the joint interest of the contracting parties coincides with the social interest. Most analyses of contract remedies have considered this case. Since $U^{B+S}(r, x)-W(r, x)=$ $-\alpha \int_{\Omega}[\theta-(x+c)] d F(\theta), \alpha$ can be regarded as a measure of the degree of the externality that a contract imposes on $T$.

The following technical assumptions are made throughout this article.

Assumption 1. All functions are twice continuously differentiable.

Assumption 2. $v^{\prime}>0, v^{\prime \prime}<0$.

Assumption 3. $v(r)-r$ has a unique global maximum at $r_{e}$.

Assumption 4. $c<v(0), \underline{\theta}<c$.

Assumption 5. $v\left(r_{e}\right)+c<\dot{\theta}$.

Assumption 2 says that $B^{\prime} \mathrm{s}$ reliance enhances the value of the good at a decreasing rate. Since when $B$ cannot get the good the value of reliance is zero, this suggests that $B$ 's reliance is specific to the contractual relationship between $B$ and $S .{ }^{25}$ Assumption 3 is made for notational simplicity. By definition, $r_{e}$ is the level of $B$ 's reliance when the probability of switching is zero. It is shown later that $r_{e}$ is the maximum level of reliance that the contracting parties are willing to make in equilibrium. Assumption 4 is made to make the problem interesting. It ensures that (i) There are always gains from trade between $B$ and $S$; (ii) Supplying the good to $T$ is not profitable for some realization of $T \mathrm{~s}$ value. Assumption 5 says that there is some realization of $T \mathrm{~s}$ valuation which is greater than the opportunity cost of supplying the good to $B$ even when $B$ 's valuation $v(r)$ is at its maximum with $r=r_{e}$.

The following two assumptions are made to simplify the presentation of this article. ${ }^{26}$

Assumption 6. In each maximization program, a unique interior maximum exists. 
Assumption 7. The first-order conditions for a maximization program completely characterize the unique maximum.

If $\theta$ and $r$ were verifiable, the social planner would choose a contingent trading rule such that, given reliance $r, S$ supplies the good to $T$ if the gain from doing so is greater than or equal to the gain from supplying the good to $B$ (i.e., $\theta-c \geq v(r)$, or equivalently, $\theta \geq$ $v(r)+c)$, and $S$ supplies the good to $B$ otherwise. Then reliance decision is made so as to maximize the social welfare given the contingent trading rule. Let $\tilde{W}(r)$ denote the social welfare given $r$ and given the efficient trading rule. Then,

$$
\begin{aligned}
\tilde{W}(r)= & \int_{\{\theta \geq v(r)+c\}}[\theta-c] d F(\theta) \\
& +\int_{\{\theta<v(r)+c\}}[v(r)] d F(\theta)-r
\end{aligned}
$$

The efficient reliance denoted by $r^{*}$ is defined as a maximizer of $\tilde{W}(r)$. Let $\Phi^{*}$ denote the first-best level of the probability of switching, and let $W^{*}$ denote the first-best level of social welfare.

Definition 1 . The first-best efficient outcomes $\left(r^{*}, \Phi^{*}, W^{*}\right)$ are defined by

$$
r^{*} \equiv \operatorname{argmax}_{\{r]} \tilde{W}(r), \Phi^{*}=1-F\left[v\left(r^{*}\right)+c\right] \text {, and } W^{*} \equiv \tilde{W}\left(r^{*}\right) \text {. }
$$

For later purposes, define $x^{*} \equiv v\left(r^{*}\right)$. It can be easily shown that $W\left(r^{*}, x^{*}\right)=W^{*}$.

Consider the buyer's reliance decision, given a contract $(p, x)$. Recall that the reliance decision is made independently by the buyer without coordinating it with $S$. On the other hand, the choice of $x$ is made for the joint interest of the contracting parties at the time of contract. Given $\alpha \in[0,1]$, and a contract $(p, x)$, the reliance schedule $r(x ; \alpha, p)$ is defined as a maximizer of the buyer's expected utility function $U^{B}(r, x, p)$. In other words, $r(x) \equiv$ $\operatorname{argmax}_{(r)} U(r, x, p)$. 


\section{Definitions}

\subsection{FC rule (Freedom of Contract)}

The $F C$ rule provides individuals with the maximum power of contracts by enforcing any contractual terms stipulated by parties to a contract. Therefore, under the $F C$ rule, any stipulated damages are enforced by the courts. If the parties did not stipulate damages in the contract and breach of contract dispute arises, then it is assumed that in assessing the damages the court will use the routine contract remedy - the expectation damage measure.27

Let $x^{F}$ denote the constant damages which parties to a contract would choose in order to maximize the joint utility of them given that reliance decision is made by the buyer with the knowledge of the damages. ${ }^{28}$ Then, $x^{F}$ is enforced under the $F C$ rule, and it is called the equilibrium damages under the $F C$ rule, or simply the $F C$ damages. Let $r^{F}$ denote the reliance investment made by $B$ under the $F C$ rule. Let $\Phi^{F}$ denote the probability of switching, and $W^{F}$ the value of the social welfare under the $F C$ rule. Then, $\left(r^{F}, \Phi^{F}, W^{F}\right)$ is called the $F C$ outcome. Thus, given any $\alpha$, the $F C$ damages is defined by $x^{F} \equiv \operatorname{argmax}{ }_{\{x\}} R(r(x), x)$, and it induces the $F C$ outcome $\left(r^{F}, \Phi^{F}, W^{F}\right)$ which are defined by $r^{F} \equiv r\left(x^{F}\right), \Phi^{F} \equiv \Phi\left(x^{F}\right)$, and $W^{F} \equiv W\left(r^{F}, x^{F}\right)$

\section{ED rule (Expectation Damage measure)}

Under the $E D$ rule, the courts always apply the expectation damage measure to calculate a damage payment for breach of contract, and ignore any stipulated damages. Therefore, the parties' freedom of contract is severely restricted under the $E D$ rule. The expectation damage measure intends to protect $B^{\prime}$ s expectation interest which is his interest in having the benefit of the bargain by being put in as good a position as he would have been in had the contract been performed. In the notation of this article, it is $v(r)$ given his reliance $r$ since $v(r)=[v(r)$ $r-p]-[-r-p]$ 
Outcomes induced under the $E D$ rule can be calculated after substituting $v(r)$ for $x$ in the specification of the model. Let $r E$ be the reliance investment made by $B$ under the $E D$ rule. Then, the actual damages awarded under the $E D$ rule is $v\left(r^{E}\right)$, and let $x^{E} \equiv v\left(r^{E}\right)$. Define $\Phi^{E}$ $\equiv \Phi\left(x^{E}\right)$ to be the probability of switching, and also define $W^{E} \equiv W\left(r^{E} x^{E}\right)$ to be the value of the social welfare which is obtained under the $E D$ rule. Then, $\left(r^{E}, \Phi^{E}, W^{E}\right)$ is called the $E D$ outcome.

When a damage payment is greater than the value of expectation interest, it is said to be over-compensatory or a penalty clause. For a formal expression, assume that $x$ is the level of gross damage payment which is stipulated by the contracting parties and assume that $B$ makes his reliance at $r$. If $x>v(r)$, then $x$ is said to be over-compensatory. Note that this is a property of a particular $x$, and not of a rule.

\section{PD rule (Penalty Doctrine)}

The long-standing judicial policy regarding stipulated damages can be summarized as the 'penalty doctrine' which states that only stipulated damages which are reasonable in light of the anticipated or actual loss caused by the breach are enforceable, while unreasonably large stipulated damages are unenforceable as penalties in which case the rest of the agreement remains enforceable, and the remedies for breach are determined by routine legal remedies.

This is reflected in the formulation of the Restatement (Second) of Contracts : Damages for breach by either party may be liquidated in the agreement but only at an amount that is reasonable in the light of the anticipated or actual loss caused by the breach and the difficulties of proof of loss. A term fixing unreasonably large liquidated damages is unenforceable on grounds of public policy as a penalty. ${ }^{29}$

This doctrine must be made operational in order for it to be analyzed within the formal model. The following is an attempt to operationalize it. 
Definition 2. Under the $P D$ rule, if the stipulated damages are not over-compensatory, then they are enforceable, and otherwise, the expectation damage measure is applied. ${ }^{30}$

Formally, let $x^{P}$ denote the constant damages which parties to a contract would choose in order to maximize the joint utility of them under the $P D$ rule. Then, the amount of damages actually awarded under the $P D$ rule is $\min \left\{x^{P}, v\left(r^{P}\right)\right\}$, where $r^{P}$ denotes the reliance investment made by $B$ under the $P D$ rule. It is denoted by $\bar{x}^{P}$, and it is called the equilibrium damages under the $P D$ rule. Let $\Phi^{P}$ denote the probability of switching, and $W^{P}$ the value of the social welfare under the $P D$ rule. Then, $\left(r^{P}, \Phi^{P}, W^{P}\right)$ is called the $P D$ outcome.

The focus of the following analyses is to understand the nature of the penalty doctrine by comparing outcomes which can be obtained under the three rules defined above. Efficiency comparison of the rules is conducted by comparing the relative values of the social welfare obtained under the rules. The $X$ rule is said to be more (less) efficient than the $Y$ rule if $W^{X}>$ (<) $W^{Y}$.

\section{Two Special cases}

\subsection{When the court has perfect information}

When the court has perfect information on the contract situation, the court may be able to implement the first-best outcomes by appropriately choosing damage measures. It has already been shown in the literature that the expectation damage measure induces efficient breach decisions when the promisee's reliance is fixed. It has been also shown that when the promisee's reliance is variable, the first-best outcomes can be implemented by awarding constant damages of which level is the promisee's expectation interest which would have been had he made an efficient level of reliance. ${ }^{31}$ The following result essentially confirms these established results in a more general environment in which there is an externality. 
Proposition 1. When there is an externality, the first-best outcomes can be implemented by awarding a constant damage payment whose value is the promisee's expectation interest which would have been had the promisee made an efficient level of reliance (i.e., for any $\alpha \in(0,1]$, if $x=v\left(r^{*}\right)$, then $\left.(r, \Phi, W)=\left(r^{*}, \Phi^{*}, W^{*}\right)\right)$.

Proof: Omitted.

In order to implement this rule, however, the court is required to know the value of $v\left(r^{*}\right)$ whose knowledge in turn presupposes the knowledge of the value of $r^{*}$ as well as the function $v(\cdot)$. To calculate the value of $r^{*}$, one has to solve the problem of maximizing the social welfare function $W(r)$. Thus, the court is required to know not only the promisee's damage schedule $v(\cdot)$, but also the promisor's cost schedule and the distribution of $\theta$.

In the remainder of this article, I consider the cases in which this information is incomplete. In particular, it is assumed that the court knows only the promisee's actual damages as well as the terms of contract so that Proposition 1 is not applicable. This informational requirement is necessary, however, in order to examine the economics of the three rules of damages. If the court did not know the promisee's actual damages, the court could not calculate the expectation damages. On the other hand, without the knowledge of the terms of contract, the $F C$ rule or the $P D$ rule cannot be implemented.

\subsection{When there is no externality (when $\alpha=0$ )}

Since this case has been studied extensively in the literature, only a brief consideration is given. ${ }^{32}$ Major results for this case are summarized in Proposition 2. 
PROPOSITION 2. Assume that there are no externalities (i.e., $\alpha=0$ ).

1) The $F C$ rule can implement the first-best outcomes.

2) The $P D$ rule can also implement the first-best outcomes.

3) The ED rule cannot implement the first-best outcomes unless the promisee's reliance is

fixed since it induces the promisee to make too great a reliance investment.

Proof: Omitted.

Note that when there are no external effects from the contract, the joint interest of the contracting parties coincides with the social welfare. Also note that regardless of the presence of the externality, the first-best outcomes can implemented by awarding the constant damage payment that is set at the value of the expectation interest had the buyer made an efficient level of reliance (Proposition 1). When there are no externalities, the contracting parties are willing to stipulate this constant damage payment in the contract which will maximize their joint utility. This proves that the $F C$ rule can implement the first-best outcomes.

Since the $F C$ rule implements the first-best, there is no need to constrain the range of enforceable stipulated damages. In particular, since the $F C$ damages turn out to be justcompensatory (at least it is not over-compensatory), it is enforceable under the $P D$ rule, and thus the first-best outcomes can be implemented under the $P D$ rule.

The performance of the $E D$ rule depends on whether the promisee $B$ makes a reliance investment or not since, if he does so, it induces him to over-rely. Otherwise, the ED rule implements the first-best outcomes. ${ }^{33}$

The lesson from the analysis of this subsection is that when there are no externalities, providing contracting parties with the maximum freedom of contract by enforcing any stipulated damages is socially optimal, while partially restricting the freedom of contract by using the penalty doctrine is also socially optimal, since the restriction is not binding. On the other hand, completely restricting the freedom of contract by relying only on the expectation damage measure can be socially suboptimal. 


\section{Analyses}

The main focus of this section is to characterize and compare the efficiency performances of the three rules of awarding damages when there are externalities (i.e., $\alpha \in(0,1])$ and the court has imperfect information. Since the analysis is complicated, Subsection 5.1 considers the case in which reliance is fixed. The case in which reliance is variable is analyzed in Subsection 5.2. Before proceeding further, it is useful to have the following key lemma.

LEMMA 1. When there are externalities, the contracting parties would like to choose a constant damage payment $x$ which is greater than or equal to the one the social planner would like to choose, other things being equal (i.e., for all $\left.\alpha \in(0,1], U^{B+S_{x}}(r, x) \geq W_{x}\left(r_{x} x\right)\right)$.

Proof: Partially differentiating $U^{B+S}(r, x)$ in (6) and $W(r, x)$ in (7) with respect to $x$ yields $U^{B+S}{ }_{x}(r, x)=f(x+c)[v(r)-x]+\alpha[1-F(x+c)]$ and $W_{x}(r, x)=f(x+c)[v(r)-x]$. Since [1-F(x+c)] $\geq 0$, I have $R_{x}(r, x) \geq W_{x}(r, x)$ for all $\alpha \in(0,1]$. Q.E.D.

The logic behind Lemma 1 is as follows. Recall that the equilibrium bidding price $z(\theta, x, \alpha)$ is increasing in $x$ from (1). In other words, by committing, in the initial contract, to a high level of constant damages, the parties to a contract could raise the price that a third party has to pay to induce a breach of contract to the extent that the damages is enforced. Note that the high level of constant damages generates an (external) cost to $T$ which is not considered by the contracting parties when the parties stipulate it in their contract.

This logic can be reinterpreted by thinking of the contracting parties as a monopoly in stipulating damages in the contract. The monopoly faces a consume-or-sell decision of the seller's contractual capacity, and it tries to set its asking price above the competitive level when there is an externality. The monopoly could effectively raise its asking price, which is $z(\theta, x, \alpha)$, by stipulating high damages. Therefore, the social inefficiency resulting from the enforcement of a penalty clause can be viewed as the social cost of monopoly. 


\subsection{When reliance investment is fixed}

Since the buyer's reliance investment is fixed at $r$ in this subsection, $r$ can be dropped from the formal specification of the model. The main result of this subsection is now stated and discussed.

PROPOSITION 3. Assume that reliance is fixed, and that there are externalities (i.e., $\alpha \in(0,1])$.

1) The $F C$ rule cannot implement the first-best outcomes. Specifically, under the $F C$ rule, the contracting parties have an incentive to stipulate a penalty clause whose enforcement puts an external cost to potential competitors, and thus induces an inefficiently low level of switching (i.e., $x^{F}>\nu, \Phi^{F}<\Phi^{*}, W^{F}<W^{*}$ ).

2) The $P D$ rule can implement the first-best outcomes. By putting an upper limit on the enforceable stipulated damages, the $P D$ rule can eliminate the aforementioned inefficiency of the $F C$ rule. In particular, the actual damage payment is the value of the promisee's expectation interest (i.e., $\bar{x}^{P}=v, \Phi^{P}=\Phi^{*}, W^{P}=W^{*}$ ).

Proof: See the Appendix.

The first result of Proposition 3 shows that stipulating penalties is in the interest of parties to a contract even though it is inefficient from the viewpoint of society. ${ }^{34,} 35$ The proof of this result relies heavily on Lemma 1.36 The basic intuition is similar to the one behind Lemma 1 . The parties to a contact would like to commit to a high level of constant damages which would be enforceable under the $F C$ rule. Since it imposes an external cost upon $T$ by raising the equilibrium bidding price, it induces an inefficiently low level of switching of buyers (inefficient breach decision).

The second result of Proposition 4 shows that the $P D$ rule has some efficiency basis in that it eliminates social inefficiencies by restricting the range of enforceable stipulated 
damages. Since the parties have an incentive to stipulate a higher damages than the courts would like to enforce (Lemma 1), putting a cap on enforceable stipulated damages would improve the social welfare. Specifically, under the $P D$ rule, the value of the cap is the value of $B^{\prime}$ s expectation interest, and it becomes binding so that it implements the first-best outcomes.

The lesson from the analysis of this section is that providing the maximum power of contract (i.e., complete freedom of contract) could be socially harmful since the enforcement power can be used to promote socially objectionable activities, while some restriction on the power can improve social welfare when there are externalities.

Incidentally, Proposition 3 can be helpful in explaining why the courts have been concerned only about over-compensatory stipulated damages, not about under-compensatory stipulated damages. The reason is that the parties to a contract have no incentive to understipulate in this model. ${ }^{37}$ If the parties under-stipulated, it would generate external benefits to $T$ by lowering the equilibrium bid price so that, over a broader range of contingencies, he could make a bid and get the good, and furthermore $B$ would be under-compensated in those cases.

One corollary of Proposition 3 is that even when there are extemalities, the $E D$ rule can implement the first-best outcomes as long as reliance is fixed. Based on this observation, one may argue that the $E D$ rule is sufficient in mitigating the social inefficiency of the $F C$ rule, and thus the $P D$ rule per se is not necessary. As the analysis of the next sub-section shows, however, this argument is not correct when reliance investment is variable, and the $E D$ rule suffers from the over-investment problem.

\subsection{When reliance investment is variable}

This case in which reliance investment is variable is interesting because first, it is a more realistic case than the case with a fixed-reliance, and second, it provides a model in which the 
$P D$ rule and the $E D$ rule can be compared. The following lemma is useful in analyzing the additional complications arising from the introduction of $B$ 's reliance decision.

LEMMA 2. When there are externalities, both the promisee $B$ and the social planner would like to choose the same level of his reliance $r$, other things being equal (i.e., for all $\left.\alpha \in(0,1], U^{B}{ }_{r}(r, x) \equiv W_{r}(r, x)\right)$.

Proof. By partially differentiating both $U^{B}(r, x)$ in (3) and $W(r, x)$ in (7) with respect to $r$, it is obtained that $U^{B}{ }_{r}(r, x) \equiv v^{\prime}(r)-1-[1-F(x+c)] \nu^{\prime}(r) \equiv W_{r}(r, x)$. Q.E.D.

Lemma 2 says that the reliance investment issue can be separated from the externality effects. For example, it is expected that the social inefficiency of the $F C$ rule due to the externality can be still obtained with the introduction of the reliance investment. In particular, Lemma 2 says that once a constant damage level is given, both $B$ and the social planner would agree to the same level of $r$. Therefore, any possible difference between the actual level of reliance chosen by $B$ and the level of reliance the social planner would choose is due to the divergence between the $F C$ damages and the socially efficient damages.

Since constant damage measures are invariant with respect to $B$ 's reliance investment, a major complication when $B$ 's reliance is considered is the fact that both the $E D$ rule and the $P D$ rule which is related to the expectation damage measure depend on his reliance investment. Recall that the expectation interest of $B$ is $v(r)$.

Given this observation, an interesting issue is how the $P D$ rule affects $B$ 's reliance decision and final outcomes. Note that under the PD rule, the parties' stipulated damages are enforceable if and only if they do not exceed $B$ 's expectation interest which in turn depends on the level of his reliance. Thus, $B$ may have an incentive to over-rely in order to relax the constraint (i.e., to increase the value of the cap on the enforceable stipulated damages). This issue is addressed in the following proposition. 
PROPOSITION 4. Assume that reliance is variable and that there are externalities (i.e., $\alpha \in(0,1])$.

1) The $E D$ rule cannot implement the first-best outcomes because it induces the promisee to over-rely (i.e., $r^{E}=r_{e}>r^{*}, \Phi^{E}<\Phi^{*}, W^{E}<W^{*}$ ).

2) The $P D$ rule cannot implement the first-best outcomes because it also induces the promisee to over-rely. However, the outcomes induced by the $P D$ rule are at least as efficient as the outcomes induced by the $E D$ rule (i.e., $r^{*}<r^{P} \leq r^{E}, \Phi^{*}>\Phi^{P} \geq \Phi^{E}, W^{*}>W^{P} \geq W^{E}$ ). ${ }^{38}$

Proof: See the Appendix.

The first result of Proposition 4 is a direct extension of the standard over-investment result of the $E D$ rule to the case in which there is an extemality. The reasoning is as follows. The efficient level of reliance is calculated by taking into account the possibility that $T$ may observe high enough valuation so that supplying the good to $T$ is more efficient than supplying the good to $B$. Under the $E D$ rule, however, $B$ is in fact guaranteed his expectation interest so that $B$ sees his reliance as an investment with a certain payoff and thus over-relies.

The argument behind the second result of Proposition 4 is subtle. Only the rough idea is given here. Recall that when there is no externality, the $P D$ rule induces the promisee to make the efficient reliance investment, and the $E D$ rule induces him to make over-investment (Proposition 2). The intuition behind this result is that the stipulated damages under the $P D$ rule is invariant with respect to his reliance, while the expectation damages is variant.

Even when there is an externality, this argument is still valid. There is, however, one more complication in that the $P D$ rule will induce over-investment for the following reason. Under the $P D$ rule, the parties' stipulated damages will be enforced if and only if it does not exceed $B$ 's expectation interest. Since his expectation interest depends on the level of his reliance, $B$ has an incentive to over-rely in order to relax this constraint. It is shown in the proof of Proposition 4 that the degree of over-reliance under the $P D$ rule is less than that under the $E D$ rule. 
It turns out that the enforceable stipulated damages under the $P D$ rule take values between $v\left(r^{*}\right)$ and $v\left(r_{e}\right)$ depending on the value of $\alpha$, and it induces $B$ to make a reliance investment such that the damages are equal to the value of $B$ 's expectation interest. For example, if $v(\bar{r})$ has been stipulated within the bounds, then the resulting reliance level is $\dot{r}^{39}$ Therefore, the $P D$ rule implements at least as efficient outcomes as the $E D$ rule does by inducing a reliance level between $r^{*}$ and $r_{e}$, depending on the value of $\alpha$.

It must be emphasized that the parties to a contract strictly prefer stipulating a damage payment rather than not stipulating it (thus letting the actual damages to be determined by the expectation damage measure). The reason is that the parties themselves do not like the overreliance result under the $E D$ rule. This preference can be reflected in the choice of the stipulated damages which will be enforced, if not over-compensatory, under the $P D$ rule. Put it another way, an advantage of the $P D$ rule relative to the $E D$ rule is the fact that the $P D$ rule can utilize the private information the parties have, while the $E D$ rule ignores such information by ignoring any stipulated damages.

Now for completeness, consider the performance of the $F C$ rule when reliance is variable. Since the externality effect is still present, it is expected that the $F C$ rule cannot implement the first-best outcomes. This is essentially the identical result as the one obtained in the fixed-reliance case (the first result of Proposition 3) - enforcing stipulated damages may interfere with efficient breach decisions because contracting parties have an incentive to inflate damages. Due to Lemma 2, this in turn implies that the $F C$ rule will induce the promisee to make over investment.

Without further information, it cannot be determined whether the social welfare obtained under the $F C$ rule is greater or less than the social welfare obtained under the $P D$ rule since both rules cannot implement the first-best outcomes. The main reason for this indeterminacy is that the $F C$ rule induces an inefficiently low level of switching (with the resulting overreliance), while the $P D$ rule as well as the $E D$ rule induces $B$ to over-rely (with the resulting inefficient breach). 
The following two hypothetical cases may provide some idea of it. First, if $B$ 's reliance were not specific to the contractual relationship, then social welfare under the $E D$ rule would be greater than social welfare under the $F C$ rule (i.e., for all $\alpha E(0,1]$, if $v^{\prime}(r) \equiv 0$, then $W^{E}>$ $W F$ ). This is true because $B$ 's reliance does not cause any problem in that case, even under the $E D$ rule. Second, if there were no externalities, then social welfare under the $E D$ rule would be smaller than social welfare under the $F C$ rule (i.e., $W^{E}<W^{F}$ ). This is true because the $E D$ rule induces over-reliance, while the $F C$ rule implements the first-best outcomes (i.e., when $\alpha=0, W^{F}=W^{*}$ from Proposition 2). ${ }^{40}$

\section{Application to tort law : tort of interference with contract}

Recall that it has been assumed that the promisee $B$ recovers from the promisor $S$ for breach of contract, but $B$ could not directly recover from the third party $T$ who induces the breach of contract. Since $B$ and $T$ do not have a contractual relation, the usual contract rule cannot be applied. ${ }^{41}$ Since the case of Lumley v. Gye, however, a tort liability for intentional interference with a contract has been applied to such cases and $B$ could directly recover from $T$ not only the usual contract damages but also punitive damages. ${ }^{42,}{ }^{43} \mathrm{Here}$, punitive damages are defined as money damages that exceed the plaintiff's (the promisee's in this article) actual losses.

Since $S$ and $T$ could agree that $T$ will indemnify $S$ if $S$ is called upon to pay the damages, the identity of the party who pays the damages to $B$ is not important. For example, suppose that when $B$ recovers only from $S, T$ has to pay $x+y$ to $S$ in order to induce a breach and $S$ has to pay $x$ (from the receipt $x+y$ ) to $B$ for the contract damages. When $T$ could hold the reserve, $T$ will pay $x$ directly to $B$ and pay $y$ to $S$ so that final outcomes are the same in each case. Therefore, the relevant question is not whether to apply contract law or tort law to such a case, but what would be the appropriate damages $B$ should recover. 
Therefore, in the context of this model, punitive damages in tort law are similar to overcompensatory (stipulated) damages in contract law. One difference is that the former is awarded by the court, while the latter is stipulated by the contracting parties. The analysis of this article suggests that for efficiency purposes, only contract damages should be awarded, and punitive damages, which are by definition over-compensatory, could induce social inefficiencies in the forms of inefficiently low levels of switching and over-reliance. ${ }^{44}$

Tort recovery is intended to substitute legal action for personal vengeance and to provide an incentive to avoid wrongdoing in the future. ${ }^{45}$ It must be noted that contract damages not only compensate for pecuniary loss, but also operate as a substitute for personal vengeance and act to deter other (inefficient) contract breaches. ${ }^{46}$

\section{Conclusion}

It has been often claimed that the expectation damage measure must be a routine damage measure since it induces an efficient breach decision given reliance. This conclusion is reached without explicitly considering the possibility that parties to a contract may stipulate a damage level in their contract. In order to construct a complete theory of damage measures for breach of contract, one has to consider what the courts should do when facing stipulated damages (as well as what the courts should do when the stipulated damages are not available). The penalty doctrine has been one response in the tradition of the common law.

This article provides a formal framework in which damage measures for breach of contract are examined in a coherent way, and then analyzes the efficiency implication of this long-standing judicial policy regarding stipulated damages. In this article, three different rules of awarding damages have been considered. Table 1 summarizes the analysis of the efficiencies of the rules.

As Table 1 shows, the $P D$ rule is at least as efficient as the $E D$ rule, and the former is more efficient than the latter when reliance investment is variable. Furthermore, the $P D$ rule 
is at least as efficient as the $F C$ rule, except when the reliance investment is variable and there are externalities in which case the two rules cannot be ranked. In particular, the $P D$ rule is more efficient than the $F C$ rule when reliance investment is fixed and there are externalities. These observations provide an economic explanation on the nature of the penalty doctrine, and clarify some of the puzzling aspects of the doctrine.

An advantage of the $F C$ rule is that it allows the courts to use the private information of the parties to a contract in determining the damages for breach of contract. A shortcoming of the $F C$ rule is that it may allow the parties to commit to a socially objectionable activity (e.g., a penalty clause which induces low level of switching). On the other hand, the $E D$ rule does not allow the courts to exploit the parties' information since any stipulated damages are ignored, and thus the problem of a low level of switching does not occur. A drawback of the $E D$ rule is the fact that the promisee over-relies under the rule. The $P D$ rule could mitigate this over-reliance problem since the parties' private information can be effectively used under the rule, and it could mitigate the problem of low level of switching by placing a cap on the enforceable stipulated damages. The main lesson from this analysis is that the judicial system does not always provide individuals with its maximum power in enforcing contractual terms, and furthermore some restriction on the freedom of contract could be socially efficient.

This article is concluded by mentioning directions for future research. First, several familiar remedies for breach of contract can be compared in the framework of this article. For example, it would be useful to compare the efficiencies of reliance damage measures and restitution damage measures with those of damage rules considered in this article when there are externalities. Second, the assumption that no resale between buyers is not allowed may be relaxed in order to examine whether other remedies such as specific performance or injunction might perform better than the damage rules considered in this article. Third, recall that it has been assumed that renegotiation of the contract is not allowed. The implication of relaxing this assumption for the results of this article would be interesting. ${ }^{47}$ 
reliance investment

$$
(\alpha=0)
$$

$(\alpha>0)$

Fixed

$F B \sim F C \sim P D \sim E D$

$F B \sim P D \sim E D>F C$

Variable

$F B \sim F C \sim P D>E D$

$F B>P D \geq E D$

and $F B>F C$

In Table 1, $X \sim Y$ means that the $X$ rule is as equally efficient as the $Y$ rule, $X>Y$ means that the $X$ rule is more efficient than the $Y$ rule, and $X \geq Y$ means that the $X$ rule is at least as efficient as the $Y$ rule. $F B$ denotes the first-best contingent rule; $F C$, the rule of freedom of contract; $P D$, the rule of penalty doctrine; $E D$, the rule of expectation damage measure.

TABLE 1. Efficiency Comparison of the four rules of awarding damages 


\section{Appendix.}

The proofs of Proposition 3 and 4 follow.

\section{Proof of Proposition 3.}

1) Fix $\alpha>0$. Recall that the $F C$ damages is defined by $x^{F} \equiv \operatorname{argmax}_{(x)} U^{B+S(r, x) \text {, where }}$ $U^{B+S}(r, x)=v(r)-r+[1-F(x+c)][x-v]+(1-\alpha) \int_{\Omega}[\theta-(x+c)] d F(\theta)$. Therefore, $x^{F}$ is characterized by the following first-order condition :

$$
U^{B+S}{ }_{x}(x)=f(x+c)[v-x]+\alpha[1-F(x+c)]=0 .
$$

Since $[1-F(x+c)] \geq 0$ for any $x$, and $\alpha>0$, I obtain $x^{F} \geq v$ from (A1). By Assumption 5, I have $1-F(v+c)>0$ so that $x^{F} \neq v$. This implies $x^{F}>v$. From this result, I have $\Phi^{F}<\Phi^{*}$ since $\Phi(x) \equiv 1-F(x+c)$ is decreasing in $x$. Hence, I have $W^{F}<W^{S}$. This completes the proof of the first result of Proposition 3.

2) Recall that the actual damages award $\dot{x}^{P}$ under the $P D$ rule is $\min \left\{x^{P}, v\right\}$. Hence, it suffices to check whether the parties have any incentive to stipulate a sum less than $v$, i.e., $x^{F}<v$. Since $x^{F}>v$ has already been shown above in 1 ), I have $x^{P} \geq v$, and thus $\bar{x}^{P}=\min$ $\left\{x^{P}, v\right\}=v$. Therefore, I have $\Phi^{P}=\Phi^{*}$, and $W^{P}=W^{*}$. Q.E.D.

\section{Proof of Proposition 4.}

1) By Definition 1, the efficient reliance $r^{*}$ is characterized by the following first-order condition.

$$
v^{\prime}(r)-1-[1-F(v(r)+c)] v^{\prime}(r)=0
$$

On the other hand, the equilibrium reliance schedule $r(x)$ is characterized by

$$
v^{\prime}(r)-1-[1-F(x+c)] v^{\prime}(r)=0
$$


Under the $E D$ rule, the damages awarded is $v(r)$ for any $r$. Hence, $B$ 's expected utility (from (3) in the text) can be written as $U^{B}(r, x, p)=v(r)-r-p$. Hence, $r^{E}$ is characterized by the following first-order condition

$$
U_{r}^{B}(r, x, p)=v^{\prime}(r)-1=0
$$

which gives $r^{E}=r_{e}$, by Assumption 3, and thus $r^{E}>r^{*}$ from the comparison of (A2) and (A4). Next, I have $\Phi^{E} \equiv 1-F\left(x^{E}+c\right)=1-F\left(v\left(r^{E}\right)+c\right)<1-F\left(v\left(r^{*}\right)+c\right) \equiv \Phi^{*}$, where the inequality is obtained from $r^{E}>r^{*}$ and $v^{\prime}>0$. Given these results, it is obvious that $W^{E}<$ $W^{*}$. This completes the proof of the first result of Proposition 4.

2) The proof of the second result of Proposition 4 is complicated. The proof is divided into several steps.

[Step 1]

Define a function $\dot{r}$ by $v(\dot{r}(x)) \equiv x$, i.e., $\dot{r}$ is the inverse function $v^{-1}$ of $v$. Given any $x$, the value of $\dot{r}(x)$ is critical since if $B$ relies at any $r \geq \dot{r}(x)$, then the stipulated sum $x$ is enforceable, while if $B$ relies at any $r<\dot{r}(x)$, then it is unenforceable and the expectation damage measure is applied under the $P D$ rule.

Note that for any $x, r(x) \leq r_{e}$ from the comparison of (A3) and (A4). If $x>H\left(r_{e}\right)$, then it is over-compensatory and thus it is unenforceable under the $P D$ rule in which case the expectation damage measure is applied so that $r^{P}(x)=r_{e}$.

Next, consider any $x \leq H\left(r_{e}\right)$. As it has been mentioned in the previous paragraph, if $B$ made a reliance investment at any $r<\bar{r}(x)$, then the expectation damage measure is applied. In that case $B$ would have incentive to rely at $r_{e}$ which is greater than or equal to $\bar{r}(x)$ so that there is a contradiction. Hence, $B$ has an incentive to rely at the level which is at least $\dot{r}(x)$. Since $r(x)$ is the level of reliance that $B$ wants to make, I have $r^{P}(x)=\max \{\dot{r}(x), r(x)\}$. Thus, I have : 
LEMMA A. If $x>H\left(r_{e}\right), r^{P}(x)=r_{e}$, while if $x \leq H\left(r_{e}\right), r^{P}(x)=\max \{\dot{r}(x), r(x)\}$.

Proof of Lemma A : As above. Q.E.D.

[Step 2]

LEMMA B. If $x \geq x^{*}$, then $\dot{r}(x) \geq r(x)$, while if $x<x^{*}$, then $\bar{r}(x)<r(x)$.

Proof of Lemma B : First, $\dot{r}\left(x^{*}\right)=r\left(x^{*}\right)$ is shown. Recall that $x^{*} \equiv v\left(r^{*}\right)$. Note that from (A2), $r\left(x^{*}\right)$ is characterized by $v^{\prime}(r)-1-\left[1-F\left(v\left(r^{*}\right)+c\right)\right] v^{\prime}(r)=0$. Thus, I have $r\left(x^{*}\right)=$ $r^{*}$. By definition, $\dot{r}\left(x^{*}\right)=\dot{r}\left(v\left(r^{*}\right)\right)=v^{-1}\left[v\left(r^{*}\right)\right]=r^{*}$.

Note that from (A3), $r(x)$ is characterized by

$$
\begin{aligned}
U_{r}^{B}{ }_{r}(r(x), x)= & v^{\prime}(r(x))-1-[1-F(x+c)] v^{\prime}(r(x))=0, \text { or equivalently } \\
& v^{\prime}(r(x))-1-[1-F(v(\bar{r}(x))+c)] v^{\prime}(r(x))=0
\end{aligned}
$$

In order to compare $\dot{r}(x)$ and $r(x)$, define $\Psi(x) \equiv v^{\prime}(r(x))-1-[1-F(v(r(x))+c)] v^{\prime}(r(x))$. Then, I have

$$
\begin{aligned}
\Psi(x) & =v^{\prime}(r(x))-1-\left[1-F(v(\bar{r}(x))+c)+F(v(\bar{r}(x))+c)-F(v(r(x)+c)] v^{\prime}(r(x))\right. \\
& \left.=v^{\prime}(r(x))-1-[1-F(\nu(\bar{r}(x))+c)] v^{\prime}(r(x))+[F(v(\bar{r}(x)))+c)-F(v(r(x))+c)\right] v^{\prime}(r(x)) \\
& =[F(v(\bar{r}(x))+c)-F(v(r(x))+c)] v^{\prime}(r(x)) \quad \text { by using (A3) above. }
\end{aligned}
$$

Define $W^{P}(r) \equiv W(r, v(r))$ to be the social welfare when $x=v(r)$. As it is shown below (see $(\mathrm{A} 10)), W^{P}(r)$ can be regarded as the social welfare under the $P D$ rule. Then, I have $W^{P}{ }_{r}(r)=v^{\prime}(r)-1-[1-F(v(r)+c)] v^{\prime}(r)$. Note that $W^{P}{ }_{r}(r(x)) \equiv \Psi(x)$. Since $r\left(x^{*}\right)=r^{*}$ and $W^{P}{ }_{r}\left(r^{*}\right)=0$ by definition of $r^{*}$, I have $\Psi\left(x^{*}\right)=0$. Furthermore, I have $\Psi^{\prime \prime}<0$ since $r(x)$ is increasing in $x$ and $W^{P}{ }_{r}<0$ from the second-order condition. Thus, if $x \geq x^{*}$, I have $\Psi(x)$ $\leq \Psi\left(x^{*}\right)=0$. Therefore, if $x \geq x^{*}$, then $\dot{r}(x) \geq r(x)$ from (A6) since $F^{\prime}>0$ and $v^{\prime}>0$. Similarly, if $x<x^{*}$, then I have $\bar{r}(x)<r(x)$. This completes the proof of Lemma B. Q.E.D. 


\section{[Step 3]}

LEMMA C. Given a stipulated damages $x, B$ 's reliance under the $P D$ rule is characterized by

$$
\begin{aligned}
r^{P}(x) & =r_{e} \quad \text { if } x>v\left(r_{e}\right) \\
& =\bar{r}(x) \quad \text { if } x^{*} \leq x \leq v\left(r_{e}\right) \\
& =r(x) \quad \text { if } x<x^{*} .
\end{aligned}
$$

Proof of Lemma C: Lemma C is a direct consequence of Lemma A and Lemma B. Q.E.D.

\section{[Step 4]}

Now, consider the parties' decision on the level $x^{P}$ of privately optimal stipulated damages under the $P D$ rule. Note that if $x^{P}>v\left(r_{e}\right)$, then $\bar{x}^{P}=v\left(r_{e}\right)$, while if $x^{P} \leq v\left(r_{e}\right), \bar{x}^{P}=x^{P}$ from Lemma C. Hence, without loss of generality, any $x^{P}>v\left(r_{e}\right)$ can be analyzed as if it were $v\left(r_{e}\right)$. On the other hand, note that if $x^{P}<x^{*}$, then the constant damages $x^{P}$ is enforced without any constraints. In those cases, however, it can be shown in the first result of Proposition 3 and Lemma 2 that $x^{F}>x^{*}$. Thus the parties have an incentive to raise $x$ within the range. Therefore, without loss of generality, only those of $x$ which is in the range between $x^{*}$ and $v\left(r_{e}\right)$ can be considered.

\section{[Step 5]}

When $x^{*} \leq x \leq v\left(r_{e}\right)$, I have $r^{P}(x)=\bar{r}(x) \equiv v^{-1}(x)$ from (A7). In other words, if $x=v(r)$, where $r \in\left[r^{*}, r_{e}\right]$, then $r^{P}(x)=v^{-1}(x)=r$. Hence, the parties' decision on the stipulated damages under the $P D$ rule can be analyzed as if the parties choose $r$, instead of $x$. Once such $r$ is chosen to maximize the joint utility of the parties, then the privately optimal $x$ can be calculated by $x=v(r)$. Formally, I have 


$$
\begin{aligned}
& \text { maximize } U^{B+S}(r(x), x)=\operatorname{maximize} U^{B+S(r, x)} \\
& x \in\left[x^{*}, v\left(r_{e}\right)\right] \quad r \in\left[r^{*}, r_{e}\right] \\
& \text { subject to } r(x)=v^{-1}(x) \quad \text { subject to } x=v(r) \text {. }
\end{aligned}
$$

Thus, the latter maximization program is analyzed in this proof. By substituting $v(r)$ for $x$ in $U^{B+S}(r x)$ in (6), I define the joint utility of the parties under the $P D$ rule as :

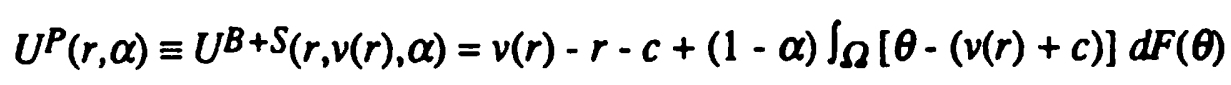

Note that in general, $x^{p}, r^{p}$, and $\Phi p$ are functions of $\alpha$. Then, $r^{P}(\alpha)$ is characterized by the following first-order condition :

$$
U_{r}^{P}(r, \alpha)=v^{\prime}(r)-1-(1-\alpha)[1-F(\nu(r)+c)] v^{\prime}(r)=0
$$

From (A9), I obtain that $r^{P}(0)=r^{*}, r^{P}(1)=r_{e}$, and $\frac{d r^{P}(\alpha)}{d \alpha}>0$. From this result, I also obtain that $x^{P}(0)=v\left(r^{*}\right), x^{P}(1)=v\left(r_{e}\right)$, and $\frac{d x^{P}(\alpha)}{d \alpha}>0$. Similarly, I have $\Phi^{P}(0)=\Phi^{*}$, $\Phi^{P}(1)=\Phi^{E}$, and $\frac{d \Phi^{P}(\alpha)}{d \alpha}<0$. In summary, I conclude that for all $\alpha \in(0,1], r^{*}<r^{P}(\alpha) \leq$ $r^{E}(\alpha)=r_{e}$, and $\Phi^{*}>\Phi^{P}(\alpha) \geq \Phi^{E}$.

Define the social welfare under the $P D$ rule by substituting $v(r)$ for $x$ in $W(r, x)$ in (7) as follows:

$$
W^{P}(r) \equiv W(r, v(r))=v(r)-r-c+\int_{\Omega}[\theta-(v(r)+c)] d F(\theta)
$$

Note that $W^{P}(r)$ is maximized at $r=r^{*}$ with $W^{P}\left(r^{*}\right)=W^{*}$ and it is decreasing for $r>r^{*}$ from the second-order condition. Also note that $U^{P}(r, 0) \equiv W^{P}(r)$. Define $W^{P}(\alpha) \equiv$ $W^{P}\left(r^{P}(\alpha)\right)$. Since $\frac{d r^{P}(\alpha)}{d \alpha}>0$, I have $\frac{d W^{P}(\alpha)}{d \alpha}<0$ with $W^{P}(0)=W^{*}$, and $W^{P}(1)=W^{E}$. In summary, I conclude that $W^{*}>W^{P}(\alpha) \geq W^{E}$. This completes the proof of the second result of Proposition 4.

Q.E.D. 


\section{Footnotes}

1 This sum of money stipulated in the contract as a damage payment is often called a liquidated damages. Although this term is popularly used, some authors limit the term to denote 'enforceable' stipulated damages. Therefore, this article defines 'stipulated damage clauses' as contractual provisions stating the dollar amount that the breaching party pays the non-breacher.

2 There have been a number of work trying to provide an economic rationale for rules of the common law. The law's refusal to enforce penalty clauses has been one of the most important counterexamples to the efficiency theory of the common law, Posner (1986, p.233).

3 Brightman (1925, p.302) argues that the parties should be able to exert the same freedom in shaping the terms of the clause of the contract which liquidates the damages that they exert in shaping the terms of any other clause of the contract. Ulen (1984, p.356) argues that stipulated damages seek to encourage contracting parties to specify how they wish disputes resolved, and there is every reason to believe that they will stipulate the most efficient remedy, considering all the factors. Epstein $(1989$, p.137) argues that where there are express provisions that govern the award of damages, these should normally be followed.

${ }^{4}$ Clarkson, Miller, and Muris (1978) consider the possibility that parties to a contract may be able to induce or prevent breach, and argue that if neither party has an opportunity or incentive covertly induce the other party to breach, stipulated damage clauses should be freely enforced.

5 For example, Goetz and Scott (1977, pp. 567 - 568) argued that obstinate insistence on the enforcement of certain penalties may result in a failure to exploit potential efficiency gains by inducing the penalized party not to breach. 
6 Corbin (1962, Section 1057, pp. 335 - 336) comments that the pendulum of judicial opinion shifts between two extremes, one holding that public interest requires frequent refusal to enforce agreements, and the other that freedom of contract is the paramount public policy ... Where a court decides in favor of enforcement, it may bolster up its decision by strong general statements as to giving effect to the intention of the parties and as to freedom of contract. In refusing enforcement, it may speak broadly about the injustice of penalties and the inequity of awarding more than compensation measured by harm suffered.

7 The situation is that the promisor can use the resources committed to the performance of the contract to produce something different and more valuable than that promised to the original promisee. Many of the examples in the legal literature are within this situation. Lumley v. Wagner. is a landmark case. Pennzoil Co. v. Texaco Inc. is a variant of this case. Another hypothetical example is that of a construction contract. A contractor $S$ promises to build a four story building on $B^{\prime}$ plot for $\$ 5,000,000$. The performance of his promise was not delegable to anyone else. Shortly afterwards $T$ asks to build a thirty-story building on $T$ 's plot for $\$ 50,000,000$. This example is due to Farnsworth (1970) and Friedman (1989).

8 The two original parties to the contract try to design things so that there is a breach if and only if the third party bid exceeds either of their valuations. Since the third party bid is less than the valuation of the third party, however, they are not doing what is in the social interest, which takes into account the full value placed on the good by the third party.

9 Atiyah (1987, p. 503) points out a lack of this kind of study by mentioning that it the mature common law of contract] was first of all deficient in its almost total neglect of the problem of externalities. Contracting parties were entitled to pursue their own interests, regardless of the effect of their contract on third parties, or the public.

10 Rea $(1984$, p.149) comments that one difficulty with Rubin's explanation is that there are numerous other areas of the common law in which courts seem to encourage use of judicial resources, even though they are supplied at little cost to private parties. 
11 The parties engage in expenditures on specific asset before the contractual performance either to prepare to use the good or to prepare to supply it. To describe this situation, it is said that the parties make reliance investments.

12 If the parties are not risk neutral, the optimal risk allocation may have to be considered. See Polinsky (1983) for a work considering the risk sharing function of the liquidated damages.

13 In the earlier version of this article, Chung (1989), a general model without these two assumptions of zero utility and zero cost is analyzed.

14 In other words, they are sufficiently complex that it would be prohibitively costly to describe them in such a way that an outside court could verify them.

15 To clearly focus on the externalities as a possible reason for unenforceability of contractual terms, it is assumed that the procedure of the bargain is not subject to any cause for formation defenses - for example, frauds, mistake, misrepresentation, duress, and unconscionability. Rea (1984) provides an argument for the penalty doctrine based on this procedural deficiency.

16 Note that the damage payment is paid from the promisor $S$ to the promisee $B$. The promisor and the outside party $T$ could agree that $T$ will indemnify $S$ if $S$ is called upon to pay the damages. The results of this chapter are not changed under this alternative specification. For further discussion, see Section 6.

17 These utilities are von Neumann-Morgenstern utility functions which are linear in wealth under the risk neutrality assumption.

18 Other damage measures such as reliance measures and restitution measures could be analyzed in the framework of this chapter. Since the space is limited, they are not considered in this chapter.

19 If more complicated contracts were allowed, the parties to a contract could write a damage rule rather than a constant. To make clear the arguments of this chapter, the possibility is ignored. 
20 The exact method of how the parties agree to a contract is irrelevant in this model. For example, it may be assumed that $B$ makes a take-it-or-leave-it offer of a contract $(p, x)$, and $S$ responds to it. The contract must satisfy $S$ s participation constraint by a suitable choice of $p$.

21 This is due to Coase theorem, Coase (1960). The point that if renegotiating cost were negligible, then a post-breach negotiation would induce efficient outcomes even when a penalty clause has been prestipulated is made in Goetz and Scott (1977) and Ulen (1984). Cooter (1982) provides a different view, however, that the absence of a rule determining the final outcome can be an obstacle to private bargains.

22 This is the specification used in Shavell (1980).

23 When $\theta$ is a private information of the outside party, it is plausible that $T$ has all the bargaining power. This specification is used in Aghion and Bolton (1987).

24 Note that $p$ does not appear in either $R(r, x)$ or $W(r, x)$.

25 If reliance investments were not specific, then it can be shown that the presence of reliance does not cause any problem so that it can be analyzed as if the parties do not rely.

26 Several technical assumptions on primitives of the model could be made to replace Assumptions 6 and 7. It would complicate the analysis, however, without providing further economic insights. In the proofs of Propositions, however, appropriate concavity assumptions are made wherever necessary, for example, a maximand is strictly concave in its argument.

27 It can be shown that in equilibrium the parties do not have any incentive not to stipulate a constant damage payment. Recall that if the parties does not stipulate a damages, then the courts will apply the expectation damage measure. Therefore, it is without loss of generality to assume that the parties always stipulate a constant damages under the $F C$ rule and the $P D$ rule.

28 In general, $x^{F}$ depends on the value of $\alpha$. To make the presentation simple, $\alpha$ is sometimes ignored as an argument of variables. 
29 This is also reflected in the formulation of the Uniform Commercial Code 2-718: Damages for breach by either party may be liquidated in the agreement but only at an amount which is reasonable in the light of the anticipated or actual harm caused by the breach, $\cdots$. A term fixing unreasonably large liquidated damages is void as a penalty.

30 The careful reading of the Restatement of Contracts may point out that, in formulating Definition 2, I have ignored the issue of the difficulties of proof of loss in enforcing stipulated damages. The rationale behind my formulation is as follows. Suppose that (expectation) damages is difficult to prove, and that parties to a contract stipulated a damage payment in the contract. In this circumstance, the court does not have any other choice than just enforcing the stipulated damages as the Restatement instructed. Note that the court cannot apply the penalty doctrine as formulated in this article since it cannot calculate the cutoff point - the expectation damages. My contribution is showing that even when the court is able to calculate the expectation damages without difficulties, there is a need for the penalty doctrine as my analysis will show.

31 Cooter (1985), Craswell (1989), and Rogerson (1983) have already shown that the constant damage payment which is set at $v\left(r^{*}\right)$ implements the first-best outcomes in a model in which only the promisee $B$ makes his reliance investment.

32 This case covers the situations in which one of the parties to a contract faces uncertain valuation (or cost) of the contractual performance. Shavell (1980) shows that these situations can be analyzed in the same way as the situation of this chapter in which one of the parties faces uncertain outside opportunity under the assumption that there are no externalities. Therefore, the analysis of the situation when there are no externalities is important not because externalities are not present in reality, but because it covers other important class of situations.

33 For example, see Shavell (1980).

34 This particular result in this subsection that the stipulated damages (under the $F C$ rule) can be socially inefficient has essentially been shown in Aghion and Bolton (1987). 
35 Cooter and Eisenberg (1985) propose the expectation theory which states that in case of breach the injured party's recovery should be measured under the damage rule the parties probably would have agreed to at the time of contract-formation if they had bargained under the ideal conditions and had addressed the issue. Given the result of Proposition 3 in this chapter, the expectation theory must be reinterpreted as, $\cdots$ the damage rule all the parties concerned (including third parties) probably would have agreed to at the time of contractformation if they had bargained and had addressed the issue.

36 In the proof of Proposition 3, it is shown that $\Phi^{F}=\left[1-F\left(x^{F}+c\right)\right]>0$. This result says that a complete blocking of switching of buyers by stipulating a very high constant damages is not in the interest of the contracting parties.

37 One possible reason for under-liquidated damages is unconscionability which is assumed away in this chapter. Restatement (Second) of Contracts, Section 356 (1982) comments that a term fixes an unreasonably small amount as damages may be unenforceable as unconscionable.

38 In each of the inequalities in 2) of Proposition 4, the equality holds if and only if $\alpha=1$.

39 The exact value of the stipulated damages depends on the value of $\alpha$. For example, when $\alpha=0$, the $P D$ rule implements the first-best outcomes, while when $\alpha=1$, the outcomes under the $P D$ rule are the same as those under the $E D$ rule.

40 It can be shown that the difference between two welfares is increasing in the degree of the externality (i.e., $\frac{d}{d \alpha}\left[W^{E}(\alpha)-W^{F}(\alpha)\right] \geq 0$ ).

41 Cooter and Ulen (1988,p. 341) observe that the rules of contract law concern relationships between people for whom the ex ante costs of bargaining are low and who have, as a result, entered into a contractual relationship; the rules of tort law concern relationships between people for whom the ex ante costs of bargaining about the harm are high and who cannot, therefore, enter into a contractual relationship. 
42 1853, 2 El. \& Bl. 216, 118 Eng. Rep. 749. The story of the case is told in Peck (1961, pp. 125 - 144).

43 For a recent case of tortious inducement of breach of contract, see Pennzoil Co. v. Texaco Inc. (1987). In this case, the jury awarded the plaintiff $\$ 10.53$ billion in damages, of which $\$ 3$ billion was punitive damages.

44 Two arguments recently made in Epstein (1987) and Friedman (1989) may be compared with the argument made in this chapter. Epstein argues that injunctions against inducement of breach or some damages in excess of actual loss may be appropriate as well. On the other hand, Friedman argues that in the case of bad-faith conversion (inducement of breach), injunctions should be allowed almost as a matter of course, while damages for actual inducement cases should seek to deprive the inducer of all gain from the transaction.

45 See Sullivan (1977, p. 219).

46 This view is also consistent with two recent arguments made in Dobbs (1980) and Perlman (1982). Dobbs (1980, p. 361) argues that there are surely cases in which the efficient breach philosophy appeals to common sense of how to maximize everyone in the community, and if this is so, the effort to negotiate an efficient breach should not be taxed with tort liability. Perlman (1982) proposes an unlawful means test that restricts tort liability to those cases in which the defendant's act is independently wrongful. It has been argued in Perlman (1982, p. 128) that where the defendant's behavior is lawful except for the resulting interference, tort theory should reflect and remain consistent with contract policies.

47 See Rogerson (1984) and Shavell (1984) for analyses of the case when renegotiation is allowed, but there are no externalities. 


\section{References}

Aghion, Philippe and Bolton, Patrick, "Contracts as a Barrier to Entry," American Economic Review, June 1987, 77, 388-401.

Atiyah, P.S., "Common Law," in John Eatwell, Murray Milgate, and Peter Newman, eds., The New Palgrave: A Dictionary of Economics, Vol.1, 501-504. New York: Stockton Press, 1987.

Brightman, Alvin C., "Liquidated Damages," Columbia Law Review, March 1925, 25, 277-304.

Clarkson, Kenneth W., Miller, Roger L. and Muris, Timothy, "Liquidated Damages v. Penalties : Sense or Nonsense ?" Wisconsin Law Review, 1978, 351-390.

Chung, Tai-Yeong, "On the Social Optimality of Liquidated Damage Clauses : An Economic Analysis," Mimeo, Northwestern University, 1989.

Coase, Ronald, "The problem of social cost," Journal of Law and Economics, October $1960,3,1-44$.

Cooter, Robert, "Unity in Tort, Contract, and Property : The Model of Precaution," California Law Review, January 1985, 73, 1-51.

— , "The Cost of Coase," Journal of Legal Studies, January 1982,11, 1-33. and Eisenberg, Melvin A., "Damages for Breach of Contract," California Law Review, October 1985, 73, 1432-1481. and Ulen, Thomas, Law and Economics, Glenview: Scott, Foresman and Company, 1988.

Corbin, Arthur L., Corbin on Contracts, Minnesota: West Publishing Co., 1963.

Craswell, Richard, "Performance, Reliance, and One-sided Information," Journal of Legal Studies, June 1989, 18, 365-401

Diamond, Peter and Maskin, Eric, "An Equilibrium Analysis of Search and Breach of Contract,I: Steady State," Bell Journal of Economics, 1979, 10, 282-316. 
Dobbs, Dan B., "Tortious Interference with Contractual Relationships," Arkansas Law Review, 1980, 34, 335-376.

Epstein, Richard A., "Inducement of Breach of Contract as a Problem of Ostensible Ownership," Journal of Legal Studies, January 1987, 16, 1-41.

_ , "Beyond Foreseeability : Consequential Damages in the Law of Contract,"Journal of Legal Studies, January 1989, 18, 105-138.

Farnsworth, E. Allan, "Legal Remedies for Breach of Contract," Columbia Law Review, November $1970,70,1145-1216$.

Friedman, Daniel, "The Efficient Breach Fallacy," Journal of Legal Studies, January 1989, $18,1-24$.

Goetz, Charles J. and Scott, Robert E., "Liquidated Damages, Penalties and The Just Compensation Principle : Some Notes on An Enforcement Model and A Theory of Efficient Breach," Columbia Law Review, May 1977, 77, 554-594.

Peck, David W., Decision at Law, New York: Conerstone Library, 1961.

Perlman, Harvey S., "Interference with Contract and Other Economic Expectancies : A Clash of Tort and Contract Doctrine," University of Chicago Law Review, Winter $1982,49,61-129$.

Polinsky, A. Michell, "Risk Sharing through Breach of Contract Remedies," Journal of Legal Studies, June 1983, 12, 427-444.

Posner, Richard A., Economic Analysis of Law, Boston: Little, Brown and Company, third edition, 1986.

Rea, Samuel A. Jr., "Efficiency Implications of Penalties and Liquidated Damages," Journal of Legal Studies, January 1984, 13, 147-167.

Rogerson, William P., "Liquidated Damages and Efficient Reliance and Breach," Mimeo, Stanford University, 1983.

_ , "Efficient Reliance and Damage Measure for Breach of Contract," Rand Journal of Economics, Spring 1984, 15, 39-53. 
Rubin, Paul H., "Unenforceable Contracts : Penalty Clauses and Specific Performance," Journal of Legal Studies, June 1981, 10, 237-247.

Shavell, Steven, "Damage Measures for Breach of Contract," Bell Journal of Economics, Autumn 1980, 11, 466-490.

_ , "The Design of Contracts and Remedies for Breach," Quarterly Journal of Economics, February 1984, 99, 121-148.

Sullivan, Timothy J., "Punitive Damages in the Law of Contract: The Reality and the Illusion of Legal Change," Minnesota Law Review, January 1977, 61, 207-252.

Ulen, Thomas S., "The Efficiency of Specific Performance : Toward A Unified Theory of Contract Remedies," Michigan Law Review, November 1984, 83, 341-403.

Restatement (Second) of Contracts, Minnesota: American Law Institute Publishers, 1982.

Uniform Commercial Code, Minnesota: American Law Institute Publishers, 1978.

Lumley v. Gye, 2 El. \& Bl. 216, 118 Eng. Rep. 749, 1853.

Pennzoil Co. v. Texaco Inc., 729 South Western. 768, 107 Supreme. 1519, 1987. 